\title{
Social Bases of Positive Responsibility
}

\author{
Dmitry A. Lipinsky \\ Doctor of Law, Professor, Deputy Rector, Director of Institute of Law of \\ Togliatti State University, Russia; E-mail: Dmitri8@yandex.ru
}

\section{Doi:10.5901/mjss.2015.v6n6p402}

\begin{abstract}
The purpose of the paper is to explore the social basis of positive legal responsibility and prove its legal nature and practical importance, as well as its connection with the rule-of-law, state concept and civil society. To achieve this purpose the following methods were applied: dialectical, formal legal, sociological, and comparative legal studies. The application of a dialectical method enables to study the phenomenon comprehensively in its interconnection with practice and its development in social relations. The use of these methods has been tested by science and practice, which testifies the efficiency of their application to legal research. The paper provides the author's definition of social and legal responsibility, offers the data of a survey on the question of positive legal responsibility and its regulatory impact. The author establishes the unified character of legal responsibility that includes a positive (voluntary) and negative (state-forced) forms of implementation. The study reveals that statutory (single) responsibility is an objectively determined, introduced by law and protected by the state duty (necessity) of legal relations participants to comply with statutory regulations, and, in case of violations, the obligation of the offender to suffer condemnation, restricting of property or personal non-property rights.
\end{abstract}

Keywords: social responsibility, positive responsibility, forms of implementation of responsibility, legal liability, legal regulations.

\section{Introduction}

Study of the phenomenon of legal responsibility is impossible without understanding its generic concept - social responsibility, 'the closest, initial abstraction, the generic concept, containing basic genetic code of any kind of responsibility. Legal responsibility should be studied in conjunction with the social one, introducing the legal specifics into the concept of social responsibility. Often while giving the definition of social responsibility philosophers and sociologists emphasize the features referring to the moral, political and other responsibilities, but partially ignoring the features of legal liability, and, in their turn, legal scholars often do not take into account the general concept of social responsibility. This is largely due to the fact that for a very long time, until the mid-60s of the twentieth century, the legal responsibility was considered to be only a result of the offense. Polemizing with legal scientists, Kosolapov and Markov (1969) rightly point out that "lawyers were carried away by 'the most retrospective responsibility': criminal responsibility for crimes. And it is this aspect of responsibility that is seen almost as the one and only, simply because the problem of responsibility as a whole, in its positive aspect has not yet been developed enough". In many ways, this statement is still relevant in the present time.

\section{Research with the Application Sociological Methods}

It is noteworthy that the opinion of the citizens about having positive responsibility differs from that of some legal scholars. We surveyed a total of 400 citizens of different ages and different social and legal status, as well as 400 experts including law teachers, lawyers, legal scholars and practitioners (judges, prosecutors, police officers). The survey of the citizens was held in the city of Togliatti in 2014. Among the surveyed experts were scholars and practitioners living in the Samara region, as well as research assistants of the Saratov Branch of the Institute of State and Law of the Russian Academy of Sciences.

Answering the questions about what could keep them from committing an offence in the future $73.4 \%$ of the respondents said: knowledge of the law; respect for the law. More than $89 \%$ of respondents compared in their daily lives in one degree or another behavior with the criminal law and other restrictions. Meanwhile almost half (41\%) of the surveyed legal scholars and practitioners obviously following scientific traditions stated that the behavior of subjects is not regulated by the prohibitive provision of the law. It turns out to be an interesting situation when the addressees of legal norms consider themselves positively responsible for their future behavior and almost half of the legal scholars do not 
consider them as such. Some of the legal scholars and practitioners believe that bans are observed from force of habit $43 \%$; due to respect for the law and the high level of consciousness $-24.5 \%$. Meanwhile the citizens (80.2\%) state that they are legally responsible to the state, implying positive responsibility for future actions, while $50 \%$ of respondents testified that the state is liable to them. Answering the control backup question "Do you bear responsibility for your behavior?" $84 \%$ of the surveyed citizens responded positively.

The above survey, in our view, confirms many theoretical statements about positive social responsibility, legal liability as forms of social responsibility which have been obtained by other methodological tools. Even Immanuel Kant (1965) wrote: "We have duties toward the humanity in ourselves and others". One can be responsible for one's past and future behavior. Acts committed by an individual can be divided into those which they have already done, and those which they can commit in the future. Literature devoted to philosophical, ethical, moral, legal issues considers two aspects of the category of responsibility: responsibility for the past behavior contrary to social norms, i.e. retrospective responsibility; and responsibility for the future behavior, i.e. prospective, positive responsibility. Leistet al. (1998) denied positive legal responsibility and argued that "jurisprudence, as well as other social sciences, cannot just use philosophical concepts and categories 'as is' without taking into account the specifics of the object of this science". Many philosophical categories (including that of responsibility) do not take into account the specifics of this or that particular branch of social sciences. However, the key features, characteristics and aspects specific to social responsibility are manifested in legal liability.

\section{Research Part with Application of Dialectical and Other Methods}

Philosophers rightly point out to lawyers that retrospective responsibility can save an individual from misconduct in the future but it cannot meet the needs of society. Therefore, the concept of responsibility, emphasizing its positive side associated with the foresight of results of one's conduct and understanding of its social significance (Gryadunova, 1979), manifested as socially-beneficial behavior seems to present a more promising viewpoint. Content characteristics of responsibility should not only assess the intended behavior, but also acting in accordance with this assessment and foresight. Ilyin (1993) calls positive and negative responsibility 'preliminary' and 'follow-up'. "Preliminary responsibility is a live sense of constant presence and callings, the pursuit of perfection. Having not yet committed an act, a person already knows about his/her responsibility ". Analysis of positive responsibility, both social and legal, has not only theoretical but also practical importance. It is more important and appropriate to warn about negative responsibility and with the help of positive responsibility to prevent undesirable behavior than to use real measures of public and state legal coercion. Interests of prevention of social deviations encourage the study of the mechanisms of formation and maintenance of socially-beneficial behavior, approved by society. One of the features of civil society is high mutual social responsibility both of an individual towards the society and of the society towards an individual. Only this problem statement can help effectively solve the problem of building a civil society and a rule of law state.

Expanding boundaries of freedom predetermined by the democratization of our society at the same time leads to the increase of constraining of the society as a whole and of an individual by the requirements and responsibilities that they have to face. Social responsibility is a measure of freedom. On the one hand, it involves freedom and is based on it, and, on the other, it limits it, forcing or urging the subject to act within the limits of provided freedom. "Consciousness freedom - choice, this Lockean triad is an aggregate description of the rational (responsible) human existence" (As quoted in: Tsarkov, 1996). Total or absolute freedom does not exist. Freedom without responsibility turns into lawlessness and chaos.

Both responsibility of an individual and the responsibility of a society and a state have social nature. It is predetermined by the social nature of relations, characteristics of an individual, his or her place in the system of social relations, peculiarities of the society itself. Radical changes taking place in our society, broadening the scope of freedom of the subjects, present to them new, higher requirements. This is due to the historical development of our society, the increasing complexity of social relations, progress in science and technology.

The concept of positive responsibility is neither a theoretical abstraction, nor it is a product of the socialist system as its opponents want to present it. It is an objective scientific description of social reality at a certain stage of development of our society. This phenomenon has not been generated by scientists, but by public relations, the need for their regulation, improvement and protection. On the objective side, social responsibility is derived from the nature of the society and an individual. They appear due to the fact that social norms lay down certain preliminary requirements for the behavior of people. Responsibility is determined by the level of public awareness, the level of social relations, existing social institutions. When a subject of social relations bears responsibility, it is predetermined by the social connections and relationships. Social responsibility expresses a certain relation between an individual and a society integrally. 
Specificity of certain types of social responsibility is determined by the nature of the social relations within which they arise and exist in their qualitative certainty.

The first fundamental work on the issue of social responsibility, as it has been repeatedly pointed out in philosophical and sociological literature, was a PhD thesis of A. Chermenina (1965). She defines social responsibility as "the relation limiting freedom of each individual for the sake of public interest; the imposition of the will of the society on the free will of an individual, redirection of his or her activity within certain limits" (Chermenina, 1965). Free will is a prerequisite for responsibility, but in our opinion, social responsibility cannot be reduced only to its positive content. In this case, positive responsibility loses one of its methods of assurance: negative responsibility. "Retrospective (negative) responsibility can be regarded as a specific method to ensure positive responsibility" (Kudryavtsev, 1986). After all, positive social responsibility, if deprived of its method of assurance, turns into a declaration and cannot perform the function of regulating social relations.

In reality, there is a relationship between an individual and the society, without which it is impossible to build a ruleof-law state and a civil society. Social responsibilities of responsible subjects correspond to the public assistance, support and protection of the activity that they are charged with and that they rightly and faithfully fulfill. Meanwhile, the ability of foresight is not responsibility itself, but the characteristic of a human psyche, its level of development. This ability characterizes a subject of social responsibility and is a condition of its implementation. All types of social norms count on conscious behavior. They have an impact on individuals able to become aware of them.

Speransky (1990), considering responsibility as a general methodological concept, emphasizes that social responsibility is divided into two subsystems of relations. The first: the responsibility is retrospective in nature and acts as a social accountability and a sanction for an act contrary to the public interest. The second subsystem includes the relationship between people, groups, communities, based on a conscious attitude to activities performed in accordance with the needs of the society and the individual. The second system is based on internal regulation of individual behavior, on relatively stable standards of communal conduct, on moral norms (Speransky, 1990). A socially responsible person is characterized by a sense of duty, but it appears to be only one of the features, and the individual's behavior is governed not only by moral, but also by legal norms, the role of which grows from year to year. Positive social responsibility is based on the requirements imposed on an individual by the society, the state, and it is expressed in socially acceptable, socially significant behavior. Moral precepts of an individual are only personality traits that characterize the individual's perception of responsibility (its subjective side). And they are not always necessary as a person can behave positively not due to one's high moral ideals, but because of the fear of being condemned by the society.

Positive responsibility is closely associated with the social activity of a person chosen on the basis of requirements for an individual stated in social norms. A social norm provides freedom, binds subjects with its requirements and at the same time limits their behavior.

Social responsibility is to be understood as the subjects of social relations' obligation to comply with the requirements of the of social norms, which is expressed in their good behavior, and in cases of irresponsible behavior that does not meet the requirements of these standards, disturbing public order, leads to deprivation of personal or material nature of the guilty person. This definition accumulates both sides of responsibility: positive and negative. Besides, it implies that the real meaning of positive responsibility is compliance by the subject of public relations with social norms, i.e. socially-beneficial approved behavior. Individuals' behavior reveals their attitude to the rules established by social norms.

Positive social responsibility presupposes not only duty and responsibility but also the socially significant behavior of the subject of responsibility. They all eventually form static and dynamic characteristics of social responsibility.

Legal literature calls positive and negative responsibility different aspects of one holistic phenomenon. Some authors write that responsibility has different aspects (positive and negative). This being said, the whole phenomenon is divided into certain types. Eminently the responsibility is the unity of positive and negative (voluntary and compulsory), where negative is a way of ensuring positive. Social responsibility is unified, but it has two forms of implementation: voluntary, manifested in the obligation of the subject to follow the social norms, his good behavior and reactions to it and compulsory, manifested in the obligation of the violator of the social norms to be subjected to a variety of measures of social and (or) state coercion, to suffer adverse consequences and implementation of these consequences.

Schematically, the substance of the voluntary forms of implementation of social responsibility can be displayed as follows: requirements laid down in the social norms - subject's awareness of qualifying standards - fulfillment of this obligation (performing socially beneficial, approved actions) - the reaction of the society (assessment - approval or encouragement). The scope of applicable approval and encouragement determines certain areas of responsibility. In its turn, this scope is established by social norms. The substance of compulsory forms of implementation of social responsibility can be presented as follows: obligation to suffer adverse effects arising from the fact of committing the 
offense - the condemnation of the violator of social norms (assessment) by the society - forcing him or her to proper behavior - enduring of the adverse effects by the offender.

Forms of implementation of the unified social responsibility are not mutually exclusive, which allows them to constitute a holistic phenomenon of social responsibility. Their commonality consists in the fact that they are set forth by the social norm, in common premises and in their manifestation in the behavior of the subject. The characteristics of this behavior are not the same. It may be contentious and can be socially approved, but socially approved behavior exists insofar as conflict behavior is forbidden by the social norm. Seemingly contradictory characteristics of these types of behavior are due to the philosophical law of the unity and conflict of opposites. However, both types of behavior are modeled in the social norms, the same way as voluntary and compulsory forms of implementation of social responsibility are modeled.

Sociological and philosophical literature in general provide a rightful interpretation of voluntary (positive) form of realization of social responsibility, but one of its features is often claimed to be the main and dominant and is emphasized when defining the responsibility. Thus for some scientists it is free will, for others - behavior, for the third - relationship with the community, for the fourth - social demands, and finally the fifth emphasize the importance of the awareness of the qualifying standards. We believe that the concept of voluntary form of implementation of social responsibility should include the following features: social responsibility reflects the relationship between the society and an individual, an individual and the society; social responsibility consists in the obligation of the subjects of a social reality to follow the rules of social norms; social responsibility is manifested in beneficial or approved behavior; social responsibility rests on conscious and volitional behavior; according to its internal (subjective) characteristics social responsibility is manifested in the mental attitude of the subject, motives, goals, emotional background; externally social responsibility is manifested as assessment of the behavior by the society (approval and (or) encouragement).

Compulsory form of realization of social responsibility is characterized by the following features: social responsibility is a social obligation to undergo measures of social influence provided by social norms; social responsibility involves social coercion; externally social responsibility is manifested as assessment of the behavior by the society and enduring adverse effects of various kinds.

In view of the foregoing we consider social responsibility to be a dialectical relationship between an individual and the society, characterized by mutual rights and obligations to comply with the requirements of social norms, their implementation, entailing approval, encouragement, and in cases of irresponsible behavior contradicting the requirements, the obligation to suffer adverse consequences and their enduring.

\section{Comparison of Social and Legal Responsibility}

Common features of social and legal responsibility can be identified on the basis of the functions and principles. Stimulating (regulatory), preventive functions of social responsibility are singled out in philosophical literature (Orekhovsky, 1978). Plakhotny (1972), Safarov (1985) emphasize that social responsibility is mainly characterized by a regulatory function. The functions of social responsibility take the form of regulatory, preventive, punitive, restorative, educational functions in legal liability (Trofimova, 2000).

Social responsibility is based on the principles of justice, humanism; need (Tsarkov, 1996). "Responsibility is a measure of freedom, justice and humanism. In these moral qualities it is most closely connected with the idea of natural law, which, as it is known, considers the moral principles as fixed and immutable, categorical imperatives that determine human behavior" (Medushevsky, 1993). Legal liability as a form of social responsibility transforms within itself the ideas of justice, humanism as universal values and is based on them, but at the same time due to its formal definiteness it proceeds from the principles of legality, individualization, inevitability, guilt of the offense (Mironenko, 2001).The principles of legality, individualization, inevitability, guilt of the offense are conditioned by the existence of the principles of justice and humanism of both social and legal responsibility.

"The social responsibility of a person is an expression of the objective dependence of the individual on society." (Bazylev, 1985). This proposition also applies to legal liability. There are relations between people, the state, groups of people, etc. that occur during their activity and that are fixed in the law. Responsibility is fixed in legal norms both horizontally and vertically. The state and the citizen, the citizens themselves are mutually responsible to each other. The mutual responsibility of the individual and the state falls into the category of a general legal principle that is enshrined in the Constitution of the Russian Federation. The principle is concretized in other regulatory legal acts and Resolutions of the Constitutional Court of the Russian Federation.

It follows from the above that the legal and social responsibilities have similar grounds, are based on the same prerequisites, have common functions and principles, reflect the relations of the individual and society, and serve the 
achievement of common goals. Legal liability has a number of specific features along with the common ones that allow to mark it out among the other types of social responsibility. Firstly, the legal liability is based on legal norms, is formally defined in details, it has the clarity and general validity; secondly, the legal liability is guaranteed by the state. Thirdly, the legal liability is provided by the state coercion or the state persuasion. Fourthly, the legal liability consequences involve government approval, incentive or conviction, and punishment. Fifthly, the legal liability is carried out in the procedural form. Not all features of legal liability have been mentioned above, but only those that enable to mark it out among other kinds of social responsibility. At the same time, we have combined the features that characterize both voluntary and state-enforced forms of implementation. The special features and characteristics that distinguish legal liability among other types of social responsibility do not come into a conflict with the general properties of social responsibility.

The interests of social deviations prevention impel the study of the mechanisms of formation and maintenance of socially useful and approved by society actions. One of the features of civil society is a high level of mutual social responsibility both of the individual to society and society to the individual, and both of the state to the individual and an individual to the state. The task of establishment of a civil society and a law-based state cannot be effectively solved without stating the problem this particular way.

As we have already mentioned, social responsibility and legal liability are related to each other as the categories of genus and species. In this conceptual row, the genus is something common in the objects constituting its species. The concept that refers to the category of "species" has the properties, characteristics of the concepts that belong to a higher level, but at the same time have their own distinctive features. There are logical contradictions in judgments of those who support only retrospective legal liability. Thus, recognizing the fact that the content of the general sociological concept includes a prospective aspect along with a retrospective one, they at the same time deny the existence of a prospective aspect of legal liability. According to traditional logic, characteristic features typical of a certain type of phenomena, will be inevitably present in specific phenomena of this class. Thus, if we give voluntary (positive) and forced (negative) forms of responsibility implementation a general sociological definition, according to the rules of logic, specific concepts of responsibility should necessarily have these forms as well. "Responsibility is a social phenomenon that has a dual nature and acts as social attitude and as the quality of an individual. Social responsibility is a product and an essential component of civil society, the society of equal free individuals. Being the need mediated by the state and law, it obtains political and legal features, forms" (Shaburov, 1992), but at the same time it does not lose its main features and characteristics.

Supporters of only negative responsibility argue that such contradictory sides, aspects, forms cannot be combined in a single concept, phenomenon, as one excludes the other. The legal liability is a phenomenon of social reality; therefore, a fundamental principle of dialectic is applicable to it as to any processes reality. That is to review all the phenomena of social life in their controversial unity and struggle. Therefore, if we approach this phenomenon from the perspective of traditional logic and dialectic, such analysis will inevitably lead to the conclusion: legal liability is integral, and its various forms of implementation are in constant "struggle". An offense exists as long as there is rightful behavior, and the state-enforced form of legal liability implementation exists only as long as there is a voluntary form of legal liability implementation.

\section{Substantiation of Legal Character of the Positive Responsibility}

Legal liability like any other kind of social responsibility is integral and involves responsibility for the future behavior (positive, voluntary responsibility) as well as responsibility for the past illegal behavior (negative, state-enforced responsibility). To allege the lack of legal liability of the voluntary implementation type equals the recognition of the fact that legal liability is not a kind of social responsibility, but it is some special "non-social type" and its exclusion from the system of regulation of social relations.

There is one question to the supporters of only compulsory form of implementation of legal liability: if there are more common features than differences between legal liability and social responsibility, then why do the studies deny the existence of voluntary forms of implementation of legal liability? This denial is contrary to the principles of historicism, the concreteness of truth, the relation of part and whole, and the philosophical law of unity and struggle of opposites, the rules of logic. Denial of voluntary forms of implementation of legal liability impoverishes the actual content of legal liability, which generates limitations in research and cannot but affects the quality of the legality and the rule of law, the development of mechanisms of lawful behavior.

The regulation of legal liability is carried out by setting the authorized and obliged behavior, prohibitions or behests to do or not to do certain actions, and the rule of law acts as an etalon of possible or proper, as well as responsible behavior. The legality or illegality of actions is estimated according to this etalon, and legal responsibility is formalized and 
determined by legal norms. The establishment of statutory (integral) responsibility takes place prior to the lawful or unlawful conduct (Chernykh, 1998). "Statutory responsibility is the objectively conditioned, established by law and protected by the state necessity (obligation) of conscious and voluntary fulfilment of legal instructions by the participants of legal relations. Being the pattern (structure, model) of actually responsible and proper behavior, it fulfils a constructive and regulatory function" (Chernykh, 1998). The positive and negative aspects of legal liability implementation represent the relation of the subjects of legal relations to the statutory responsibility and are expressed in their behavior (Chernykh, 1998). In this case, opponents of positive legal liability lose the argumentation that it is devoid of legal content. Legal liability is integrated and involves different aspects (forms) of implementation. "The law is not only a measure of legal freedom, but also a measure of legal liability. These are correlative categories ... responsibility is the same objective necessity as freedom (Matuzov, 1999).

A legal norm as a kind of a social norm that serves as the legal liability regulatory framework. Underlying reasons of legal responsibility are in the subject's involvement into social relations and in its connectivity with the requirements placed on them. These requirements are formalized in the legal norm and acquire a compulsory and authoritative character that is provided by the state enforcement. "Social responsibility is driven by interconnection between people, communities, groups" (Filatova, 1990); "the social basis of responsibility is the relation between the individual and society, social determination of the subjects' actions" (Filatova, 1990). Social relations and the resulting requirements are enshrined in legal norms, which are beginning to have reversed regulating, developing and ordering influence.

Terminological saturation and the lack of terminological clarity affect the general theory of legal liability. There is a big variety of views, approaches, aspects, and opinions, which are sometimes mutually exclusive. Positive legal liability is called perspective; introspective; legal; moderately positive, actively positive; proper performance of duties; incentive. The second aspect of responsibility is in turn called negative, retrospective, passive, and etc.

The variety of views and names can be undoubtedly explained by the complexity and multi-facetedness of the object under study. What makes it more complicated is the fact that the problem of legal liability is often limited by its "traditional" retrospective aspect. However, "traditionality of notions cannot be a weighty argument in their favor and "... does not mean their "eternity". They, as well as law in whole, personify social reality, develop, alter, and are filled with qualitatively new content" (Senyakin, 1993). We, on the contrary, believe that the research trend that reduces legal liability only to its negative aspect is dead end. It impoverishes the social value of this category, leaving aside its origins, efforts to enhance human activity, development of independence and initiative, promotion of a really responsible attitude of citizens to legal regulations. "Traditional" line of research cannot claim to be firm and infallible. It does not provide an answer to a practical question: why legal liability is often not only inefficient, but sometimes does not work at all. Therefore, while not denying the existence of retrospective responsibility, we believe it to be only a part of the overall problem of legal liability, and not a determinative one, which can be passed for the whole (Chernykh\&Lipinsky, 2005).

This causes some natural questions: Why is there no complete clarity in legal liability research? What has to be done in science to achieve this?

The answer to the first question. There is no complete clarity because juridical science has not developed a systematic research of legal liability, although some attempts have been made. All the judgments come to details negative reactions to a committed offence, which is only a consequence of irresponsibility. It is not by accident that the existing definitions of legal liability identify it with other legal categories, and most often with coercion by the state and its forms. The objective character of legal liability is not seen as the preference is given to its subjective aspects (evaluation, reaction to an offence, condemnation of conduct, etc.). The limitation of legal liability by the retrospective aspect is the main reason of everything. All the attempts to go beyond its limits are persistently rejected under groundless pretence that they allegedly complicate the issue and give nothing to science. Then why does this issue remain so complicated despite all the immense work that has been done? That is due to the fact that the current situation does not enable to achieve clarity in the research of responsibility as it is presented in a down-sized version, which leaves out of sight the issues of not the least importance. In particular, it refers to the origins, the objective character, the structure of legal liability and systematic interaction of its elements.

This implies the answer to the second question. In order to ensure completeness and clarity in the research of legal liability, it is necessary to focus on the study of its structure, which would integrate scientific views, which would form stepping stones for new solutions in the cognition of this phenomenon.

The structural method of scientific cognition is to be taken as a basis for the study of legal liability. It is necessary to use other scientific methods along with it, which include dialectical, systemic- functional, formal-logical, legal modeling method, and others.

Statutory (single), voluntary and state compulsory forms of its realization are the main elements of its structure. Systemic, dialectical interaction between them, all their "legal life" are most pronounced in legal and corresponding 
relations that should be considered in the unity of different aspects, such as institutional (static) and in factually behavioral (dynamic).

Statutory (single) responsibility is objective, established by law, is a prerequisite for the external manifestation of responsible or irresponsible behavior. The origins of responsibility lie in the state-legal regulation of social relations, which is a direct prerequisite to its establishment. This type of liability is based on the norms of law, is subject to legalization, and therefore, it is called legal, i.e. it has normative-legal character.

Establishment of a single liability (liability as an integral phenomenon, statutory liability) takes place before the fact of lawful or unlawful conduct, before its evaluation as a responsible or irresponsible. It is a general requirement for all subjects of the law, a guideline for action, for proper implementation of legal regulations, and it serves as a reference point for proper behavior and the criterion of its evaluation. According to logic, prior to responding to legally significant behavior and its evaluation as a responsible or irresponsible, the state has to determine which subjects have the responsibility, under what conditions, for what and to what extent. It also has to determine the consequences in case of a positive or negative attitude to the legal directives of the state authorities.

Statutory (single) liability is objectively determined, established by law and protected by the state obligation (necessity) of participants of legal relations to comply with prescriptions of law, and in case of its violation, the obligation of the offender to suffer condemnation and restriction of rights of property or personal non-property character. Statutory liability establishes in a normative way both voluntary and state-enforced forms of legal liability implementation. We believe that this approach to the issue meets up-to-date requirements of legal regulation of social relations, as the voluntary form of legal liability implementation is unprotected unless it is fixed in the norms of the law regarding the stateenforced form of liability implementation, and the state-enforced form of liability implementation is meaningless without the voluntarily one. We have also included (potentially) the state-enforced form of implementation in the definition of liability as an integral legal phenomenon, however, it does not mean that it is always implemented. However, it is necessary as it points out to the subject what unfavorable consequences he will face in case of breaking a norm of the law. It would be naive to believe that all subjects of social relations will comply with the norms of the law only on the basis of respect for the law. Responsibility is efficient and effective only in the interaction of its various aspects that together make up the notion of responsibility as an integral legal phenomenon.

Legal liability as an integral legal phenomenon is a guarantee and an essential part of a person's legal status. Along with other guarantees, it aims at creating real opportunities to enjoy the rights and freedoms and duly perform the duties. In other words, the statutory responsibility focuses on the fact that the use of rights and freedoms by citizens is inseparable from the performance of their duties, and should not cause damage to the interests of society and the state, as well as to the rights of other citizens. We refer to such liability as statutory (single, integral legal phenomenon) on the grounds that it is established by legislation. The current legislation formalizes the rules of responsible behavior and the consequences of misconduct. In other words, legal norms provide both the voluntary and the state-enforced form of legal liability implementation, as well as constituent elements of a lawful (responsible) behavior and constituent elements of an offense (irresponsible behavior).

The main source of the general legal status of a person, which main content is made of rights and obligations, is the fundamental law of our country - the Constitution of the Russian Federation that by law sets this status so that citizens, organizations and officials comply with constitutional norms and have responsible attitude to their requirements.

The foregoing statement indicates that such norms not only reinforce the constitutional legal relations, but also lay responsibility on the subjects of these relations. The latter flows directly from the requirements of the norms of the law and a general obligation to comply with the Constitution of the Russian Federation and other subordinate legal enactments. Consequently, the legislative establishment of statutory responsibility is necessary. The state of a subject's relation to liability cannot occur if the liability is not fixed in the norms of the law. This structural unit is a legal basis, the primary, the starting element of legal liability, the exclusion of which would mean the impossibility of the existence of legal liability in general. Legal liability cannot be imagined without the law, the appearance of the state of relation to something that does not exist becomes illusive. Legal liability is an important control system, it is set by law and is a prerequisite for implementation of legal liability in any universally recognized form.

We believe that statutory legal liability (legal liability as an integral legal phenomenon) is initially set, and voluntary and state-enforced forms of its implementation flow directly from it. The first one is more stable and fundamental. All the subjects of law and the parties involved are in the same legal status (state of responsibility) regarding statutory legal liability, they are obliged to conform their conduct to the requirements of the legislator, and they shall bear responsibility for it. Only if this principle point is complied with, the behavior can be considered legally liable, but not the offender, as it is often believed. 


\section{Conclusion}

1. Single responsibility is an objectively enshrined in the law target, a reference point for proper behavior of legal subjects and a criterion of its evaluation as a responsible or irresponsible. This allows the subject that has not committed a legally significant act to know in advance about his or her responsibility, which disciplines and allows the subject to focus on implementation of general legislative rules. If the subject complies by them, it means he or she acts legally responsibly, otherwise he or she acts irresponsibly. The consequences occur in compliance with the actions, which is consistent with the general principles of justice.

2. The exclusion of responsibility that involves various forms of realization would mean the disappearance of the orienting goal, the criterion for evaluation of legally significant behavior as responsible or irresponsible. Responsibility as an integral legal phenomenon is in a static state: It is the basis, the reason and the condition for the appearance of the voluntary form of responsibility realization and the criterion to define it as such. Without this condition, the appearance of the subsequent positive responsibility, which is a responsibility in a dynamic state, is not possible.

\section{References}

Bazylev B.T. (1985). Legal responsibility. Krasnoyarsk: Publishing House of the Krasnoyarsk University.

Chermenina A.P. (1965). The Problem of Responsibility in Ethics. (Extended abstract of candidate of philosophical science (PhD) thesis, Leningrad State University named after A.A. Zhdanov, Leningrad, USSR).

Chernykh E.V. (1998). On the Normative Nature of Legal Liability. Problems in the theory of state and law,1(10), 55-62.

Chernykh E.V., Lipinsky D.A.(2005). Legal responsibility as an integral legal phenomenon. Vestnik Samarskoi gosudar stvennoi ekonomic heskoi akademii. Samara, 1, 75-87.

Filatova T.I. (1990). Social Responsibility as a Factor of Overcoming the Alienation of an Individual. (Extended abstract of candidate of philosophical science (PhD)thesis, Kharkov State University, Kharkov, Ukraine). Retrieved fromhttp://old.rsl.ru

Gryadunova L.I. (1979). Social Responsibility of an Individual in the context of Developed Socialism. Kiev.

Ilyin I.A. (1993). Path to the Evidence. Moscow.

Kant I. (1965). Works. In 6 volumes. V. 4. Moscow: 'Mysl' Publishing House.

Kosolapov R., Markov V. (1969). Freedom and Responsibility. Moscow: Publishing House of Political Literature.

Kudryavtsev V.N. (1986). Law, Act, Responsibility. Moscow: Nauka Publishing House.

Marchenko N.M., Leist O.E. et al.(1998). General Theory of State and Law. Academic Course of Lectures. Ed. by M.N. Marchenko V. 2. Moscow.

Matuzov N.I. Law as a measure of freedom and personal responsibility. (1999). Interuniversity collection of scientific papers.Atrium. Ser. "Yurisprudentsiya»,1, 20-26.

Medushevsky A.N. (1993). History of Russian Sociology. Moscow.

Mironenko M.B. (2001). The Principles of Legal Liability in the System of Principles of Law. (Extended abstract of Candidate of Legal Science (PhD) thesis. Samara Academy for the Humanities, Russia). Retrieved fromhttp://old.rsl.ru

Orekhovsky A.I. (1978). Responsibility and its Social Nature (Methodological Aspect). Tomsk.

Plakhotny A.F. (1972). Freedom and Responsibility (Sociological Aspect). Kharkov: Publishing House of the Kharkov University.

Safarov N.S. (1985). The Problem of Moral Responsibility. Baku: Publishing House of the Dagestan State University.

Senyakin I.N. (1993). Specialization and Standardization of the Russian Legislation. (Extended abstract of Post-doctoral dissertation, Saratov Law Institute named after D.I. Kursky, Saratov, Russia). Retrieved fromhttp://old.rsl.ru

Shaburov A.S. (1992). Political and Legal Aspects of the Social Responsibility of an Individual. Extended abstract of Post-doctoral dissertation, Sverdlovsk Law Institute, Yekaterinburg, Russia). Retrieved fromhttp://old.rsl.ru

Speransky V.I. (1990). Social Responsibility in the System of Social Relations (Social Aspect). Extended abstract of Post-doctoral thesis, Moscow State University, Moscow, Russia).Retrieved fromhttp://old.rsl.ru

Trofimova M.P. (2000). Functions of Legal Liability. Extended abstract of PhD dissertation (Law). Saratov.

Tsarkov I.I. (1996). Philosophical and State-legal Views of John Locke. Moscow: MABiBD Publishing House. 